\title{
THE EFFECT OF CORTICAL UNDERCUTTING AND LONG-TERM ELECTRICAL STIMULATION ON SYNAPTIC ACETYLCHOLINESTERASE
}

\author{
NAI-SHIN CHU*, L. T. RUTLEDGE AND O. Z. SELLINGER \\ Department of Physiology and the Mental Health Research Institute, University of Michigan Medical \\ School, Ann Arbor, Mich. 48104 (U.S.A.)
}

(Accepted December 22nd, 1970)

\section{INTRODUCTION}

Partial or total isolation of the cerebral cortex was offered as a model for the study of focal epilepsy ${ }^{6}$. After weeks or months the isolated cortex became sensitive to electrical stimulation or to topically applied acetylcholine $(\mathrm{ACh})^{5}$. Isolated cortex may also sustain prolonged epileptiform afterdischarge ${ }^{9,23}$. This is one measure of supersensitivity. A causal relationship between supersensitivity and an alteration in a cholinergic system has been suggested. This is based upon the observations that there is a decrease in acetylcholinesterase activity (AChE) in isolated cortex ${ }^{11,16}$ and the decrease in $\mathrm{AChE}$ activity parallels the increase in supersensitivity ${ }^{17}$.

The expected development of supersensitivity in the partially isolated cerebral cortex may be prevented by long-term electrical stimulation of the undercut cortex ${ }^{20}$. Further, the decrease in total $\mathrm{AChE}$ activity could also be prevented by the same procedure ${ }^{4}$. These experiments suggest not only the involvement of a cholinergic system in the supersensitivity of isolated cortex but also point to a critical feature, synaptic 'use' and 'disuse'. If it is assumed that isolation leads to 'disuse'18,22, an important point to determine is whether changes in AChE activity occur at synaptic sites. Although AChE is highly concentrated in both pre- and postsynaptic membranes of cholinergic synapses ${ }^{13}$, it is also distributed in non-synaptic loci ${ }^{1,15}$.

This report attempts to define the specific intracellular locus of AChE activity changes in unstimulated undercut cerebral cortex (partial neuronal isolation) and in undercut cortex subjected to long-term electrical stimulation. Centrifugal fractionation of undercut cortical tissue localized the greatest change in activity of $\mathrm{AChE}$ in the subcellular fractions containing mainly cholinergic synaptic membranes.

METHODS

Experiments on adult cats were in 4 stages: (1) sterile surgery for cortical under-

* Present address: Laboratory of Neuropharmacology, Division of Special Mental Health Research, National Institute of Mental Health, St. Elizabeths Hospital, Washington, D.C. 20032, U.S.A. 
cutting, (2) a period of developing supersensitivity or long-term electrical stimulation, (3) an acute experiment for determining the level of supersensitivity and for the removal of cortical tissue, and (4) the subcellular fractionation and chemical analyses.

The first two stages and most of the third have been fully described ${ }^{20}$. At the conclusion of the acute experiment oil was removed, the cortical surface was flushed with ice-cold $0.25 \mathrm{M}$ sucrose, the undercut cortex and the homotopic area were quickly removed, lightly blotted, and placed in ice-cold hypotonic buffered solution containing $\mathrm{Mg}^{2+}$ ion to rupture the cells (10 $\mathrm{m} M$ magnesium acetate and $20 \mathrm{~m} M$ Tris-buffer at pH 7.2). Each piece of tissue weighed about $300 \mathrm{mg}$.

The subcellular fractionation technique used to isolate the synaptic membranes has also been described in detail ${ }^{3,21}$. Briefly, the tissue was homogenized at about $1300 \mathrm{rev} . / \mathrm{min}$ and a total of 6 excursions of the pestle made. The homogenate was centrifuged at $25,000 \times g$ for $10 \mathrm{~min}$ and the sediment resuspended in $0.25 \mathrm{M}$ sucrose yielding the total particulates (TP). Fraction TP was centrifuged on a two-step, $0.9 M$ and $1.4 M$ sucrose gradient at $63,500 \times g$ for $30 \mathrm{~min}$ in a rotor SW 25.1. The band at the sucrose interface was collected and centrifuged at $160,000 \times g$ for $50 \mathrm{~min}$. A suspension of the pellet, which contained nerve endings, mitochondrial and lysosomal membranes $^{21}$ was placed on a discontinuous sucrose gradient $(9 \mathrm{ml}$ each of $1.0 \mathrm{M}$, $1.2 \mathrm{M}$ and $1.4 \mathrm{M}$ sucrose) and was centrifuged at $63,500 \times g$ for $2 \mathrm{~h}$ in rotor SW 25.1. The bands at the 3 interfaces were collected and centrifuged at $160,000 \times g$ for $50 \mathrm{~min}$. The pellets were resuspended in $0.25 \mathrm{M}$ sucrose and the fractions designated as $1.0 \mathrm{M}$ (top band), 1.2 $M$ (middle band) and $1.4 M$ (bottom band). Sellinger and Borens ${ }^{21}$ have shown that fractions $1.0 \mathrm{M}$ and $1.2 \mathrm{M}$ are rich in synaptic membranes, fraction 1.4 $M$ contains mitochondrial and lysosomal membranes and that AChE has the highest specific activity in fraction $1.0 \mathrm{M}$.

AChE was determined by the procedure of Ellman et al. ${ }^{7}$ with acetylthiocholine iodide (Dajac Laboratories, Philadelphia, $\mathrm{Pa}$.) as substrate and protein determined according to Lowry et al. ${ }^{14}$ with crystalline serum albumin as standard.

Data were obtained from 2 intact cats anesthetized with chloralose, 4 cats with undercut cortices, 5 cats with undercut and long-term electrically stimulated cortices and from 2 rats. For reasons discussed elsewhere ${ }^{20}$, the 'amount' of supersensitivity varies. An attempt will be made below to estimate the amount or level of supersensitivity observed and to compare graphically AChE levels between cortices showing most and those showing least supersensitivity.

RESULTS

The activity of $A C h E$ in the subcellular membrane fractions

The activity (O.D.412/20 min $/ \mathrm{g}$ wet weight) of $\mathrm{AChE}$ recovered in the fractions 1.0 $M, 1.2 M$ and $1.4 M$ added up to less than $50 \%$ of the total particulate AChE. This low recovery resulted from the nature of the discontinuous gradient centrifugation procedure which precludes quantitative recoveries of fractionated components but only permits their concentration in discrete, particulate bands ${ }^{21}$. However, since

Brain Research, 29 (1971) 323-330 

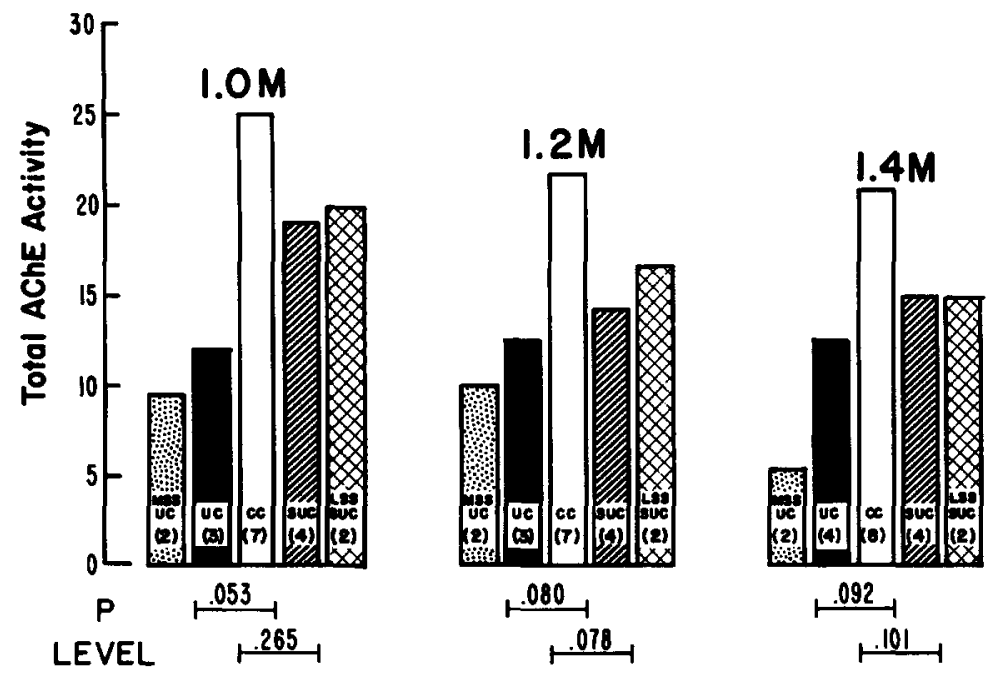

Fig. 1. Total AChE activity (O.D.412/20 min/g wet tissue) for the membrane fractions $1.0 M, 1.2 M$ and 1.4 $M$. UC, undercut cortex; SUC, stimulated undercut cortex; $\mathrm{CC}$, contralateral cortex, pooled values from UC and SUC animals; MSS, most supersensitive animals; LSS, least supersensitive animals. Numbers of experimental animals in parentheses. Statistical probability levels determined from computer programmed $t$-test.

the samples from all cortical preparations were subjected to identical treatments and, particularly, since the specific activity of AChE is known under all the conditions tested (Fig. 3), a comparison of the effects of the experimental procedures on the synaptic enzyme level appears fully justified.

Fig. 1 shows comparisons of AChE activity in the 3 fractions. AChE activity in the $1.0 \mathrm{M}$ fraction from undercut tissue was significantly lower $(P=0.053)$ than that of the pooled contralateral control fraction. The difference between the AChE activity of stimulated and contralateral tissue was not significant $(P=0.265)$. Differences between undercut and contralateral and stimulated undercut and contralateral for fractions $1.2 \mathrm{M}$ and $1.4 \mathrm{M}$ did not reach acceptable levels of significance.

In an effort to relate supersensitivity to AChE activity, a semi-quantitative rating of the degree or amount of supersensitivity was devised. A 5-point scale based upon the duration of the afterdischarge, on the local or widespread nature of the epileptiform activity and on the frequency and amplitude of the waveforms was used, and a rating from a scale of least to most supersensitive was assigned to each animal. A comparison of the two least and the two most supersensitive cases is shown in Fig. 1. In each instance, the most supersensitive cortex had less AChE activity in all 3 fractions than did the two least supersensitive tissues.

\section{Total protein and AChE activity}

To determine whether the decreased activity of AChE in the membrane fraction 

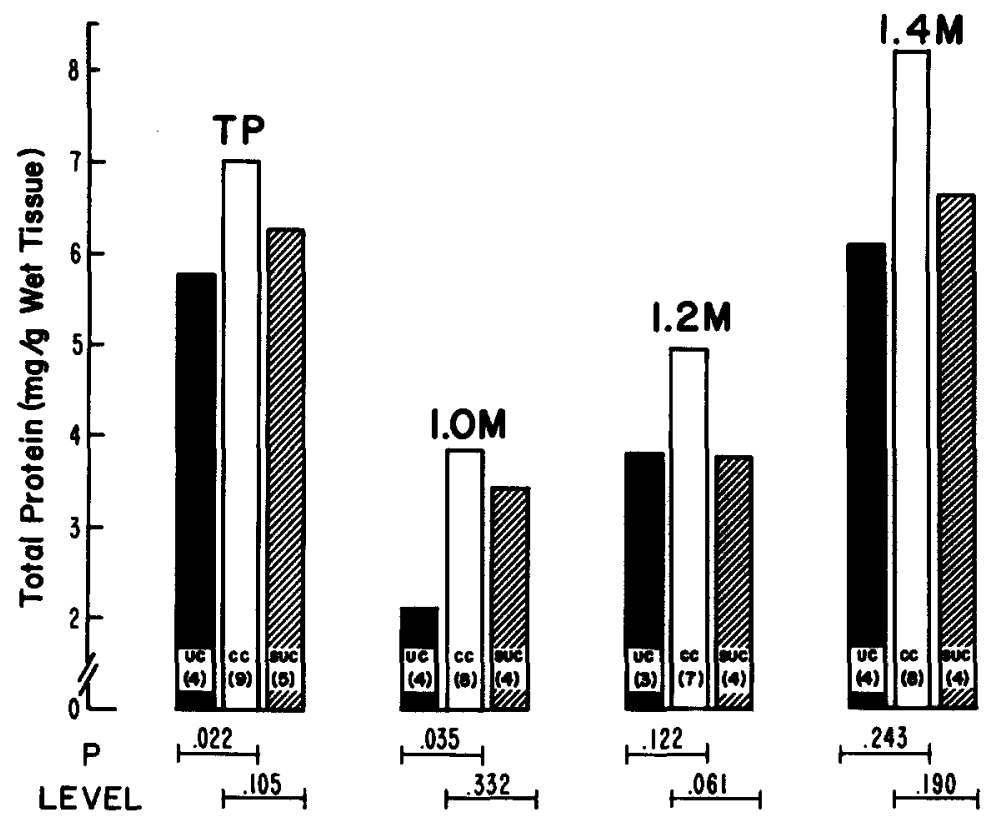

Fig. 2. Protein content (mg/g wet tissue) of the membrane fractions $1.0 M, 1.2 M$ and $1.4 M$, and of the total particulate fraction, TP. TP values are reduced to one-tenth of real value for ease of display. See Fig. 1.

$1.0 \mathrm{M}$ of the undercut cortex was accompanied by decreased amounts of tissue contained in the fraction, we measured the protein content. Fig. 2 indicates that in the TP and the $1.0 \mathrm{M}$ fraction there was significantly less protein than in the pooled contralateral fractions $(P=0.022$ and 0.035$)$. The results also revealed that long-term electrical stimulation prevented this protein loss $(P=0.105$ and 0.332$)$. There was no significant effect of undercutting on the protein content of fractions $1.2 \mathrm{M}$ and $1.4 \mathrm{M}$.

The specific activity of $A C h E$ in subcellular membrane fractions

The specific activity of $\mathrm{AChE}$ in the membrane fractions isolated from the rat was about $60 \%$ higher than that of the intact cat tissue shown in Fig. 3. In the cat, as in the rat ${ }^{21}$, fraction $1.0 \mathrm{M}$ had the highest specific activity of AChE and thus may be designated the 'cholinergic' membrane fraction ${ }^{3}$.

It can be seen in Fig. 3 that undercutting cortical tissue without stimulation decreased the specific activity of AChE in fractions $1.0 \mathrm{M}$ and $1.2 M(P=0.058$ and $0.055)$. Differences were not significant $(P=0.730$ and 0.384$)$ in the same fractions between the contralateral tissue and tissue which had received long-term electrical stimulation. Indeed, values for contralateral, stimulated, and intact tissues were virtually identical. 

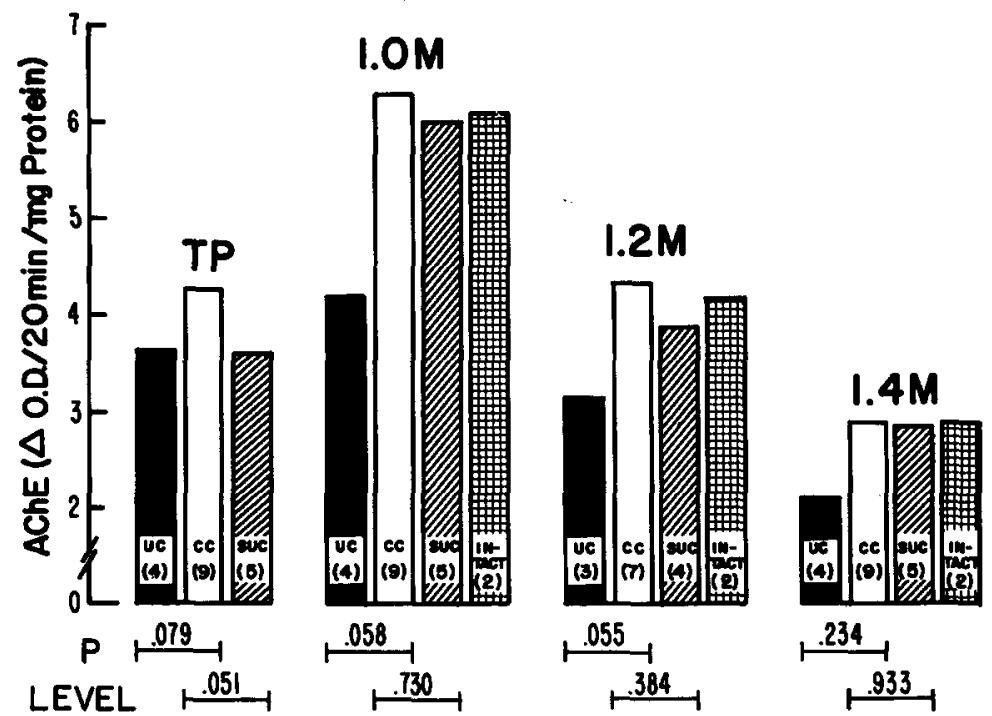

Fig. 3. Specific activity of AChE (O.D.412/20 min/mg protein) in the cortical subcellular fractions. INTACT: values from two unoperated animals. See Fig. 1.

\section{DISCUSSION}

\section{Effect of undercutting upon AChE activity}

Cholinergic innervation of the neocortex is indicated by dense fibrillar staining of AChE mainly in the lower one-half of the cortex and this staining is drastically reduced by undercutting ${ }^{12}$. Within the neocortex, cholinergic connections are mainly provided by well-stained U-fibers ${ }^{12}$. The same authors also observed that in undercut cortex some of the diffuse intracellular AChE staining had remained, although the shape of the cells was somewhat distorted. The cellular elements are likely to account for the $40-50 \%$ retention of AChE activity in the chronic, totally isolated cerebral cortex ${ }^{16}$. Higher retention ( $76 \%$ ) of $\mathrm{AChE}$ activity in chronic undercut cortex ${ }^{4}$ is probably due to contamination by the cholinergic U-fiber system. However, the decrease in the total AChE in the undercut cortex as determined in the present study by chemical assay was appreciably lower than that visualized by the histochemical method. Thus, undercutting reduced the total activity of $\mathrm{AChE}$ in all membrane fractions (Fig. 1) but only significantly $(P=0.053)$ in fraction $1.0 \mathrm{M}$. Its specific activity was also significantly reduced in membrane fractions $1.0 \mathrm{M}$ and $1.2 \mathrm{M}(P=0.058$ and 0.055 ).

Morphologically, the undercut cortex is characterized not only by loss of cellular elements but also by loss of dendritic spines and axon collaterals in the surviving neurons ${ }^{18,19}$. Since dendritic spines are sites of axodendritic synapses and axon collaterals also make synapses with cortical neurons, a greater loss of synaptic membranes than that accounted for by cellular loss would be expected. The preferential loss 
of synaptic components in the undercut cortex may be due to (1) transneuronal degeneration when afferent fibers are cut, (2) retrograde degeneration when efferents are cut, and (3) 'sequential synaptic degeneration', namely, the phenomenon of degeneration of dendritic spines (synaptic sites) in the visual cortex when optic nerves are permanently damaged $^{8,24}$.

\section{Effect of long-term electrical stimulation upon AChE activity}

Daily electrical stimulation of the undercut cortex counteracted the decrease in AChE activity in fractions $1.0 \mathrm{M}$ and $1.2 \mathrm{M}$ (Figs. 2, 3). Electrical stimulation also prevented significantly the loss of protein in fraction $1.0 \mathrm{M}$. Our previous morphological study of stimulated undercut cortex indicated that axon collaterals, dendrites and neurons were preserved by long-term electrical stimulation ${ }^{18,19}$. Although electrical stimulation produces complex effects, it is assumed that it activates the neurons either directly or synaptically and that it is the latter type of activation which most likely keeps the synapses from degenerating. The fact that the AChE activity and the protein content of the synaptic membrane fractions $1.0 \mathrm{M}$ and $1.2 \mathrm{M}$ were most affected suggests that transsynaptic activation is one effect of electrical stimulation. Since TP protein was preserved in the stimulated undercut situation (Fig. 2) another effect might be the preservation of neuronal structures.

\section{Relationship between supersensitivity and $A C h E$}

Although the number of observations is small the data are consistent with our previous findings associating supersensitivity with decreased $\mathrm{AChE}^{4}$. The present data are more definitive since it is now possible to implicate most strongly the "cholinergic' synaptic membrane fraction and to a lesser extent the $1.2 \mathrm{M}$ fraction, as the sites of greatest AChE change.

If, as it has been suggested, prolonged transmitter action is responsible for the appearance of epileptiform afterdischarge in the partially isolated cortex, there should be either a relative increase in ACh or a relative decrease in AChE or both. However, two different reports indicate that $\mathrm{ACh}$, choline acetylase and $\mathrm{AChE}$ are all decreased in the neuronally isolated cortex ${ }^{10,11}$. Since we did not observe a significant reduction in the non-synaptic membrane fraction $1.4 \mathrm{M}$, we cannot offer support for these observations.

A decrease in AChE activity in the partially neuronally isolated cortex indicates loss of cholinergic innervation and degenerative consequences. The implication for the 'use' and 'disuse' hypothesis is that the levels of AChE and supersensitivity are determined by the presence or absence of synaptic activity. In our experiments denervation resulted in loss of activity, disuse, with consequent decrease of an intracortical cholinergic mechanism. Long-term electrical stimulation can apparently preserve this cholinergic mechanism through continued synaptic use. Further elucidation of this problem is presented in the following paper². 
SUMMARY

(1) A centrifugal fractionation technique was used to study the acetylcholinesterase $(\mathrm{AChE})$ activity in a number of subcellular membrane fractions of cat cerebral cortex. In two groups of animals a marginal gyrus of each cat was undercut for a long-term preparation (chronic). Cats in one of the groups received daily electrical stimulation over the period when supersensitivity would be developing in the other group.

(2) The chronic, partial neuronal isolation of the cerebral cortex by undercutting and without long-term electrical stimulation led to a decrease of both the total AChE activity and the total protein in the subcellular fraction $1.0 \mathrm{M}$, the fraction rich in 'cholinergic' synaptic membranes. The specific activity of AChE was decreased in fractions $1.0 \mathrm{M}$ and $1.2 \mathrm{M}$.

(3) In parallel studies long-term electrical stimulation of the undercut cortex prevented the decreases in AChE activity and in the protein of the membrane fraction $1.0 \mathrm{M}$ and in specific AChE of fractions $1.0 \mathrm{M}$ and $1.2 \mathrm{M}$.

(4) Supersensitivity and loss of AChE activity were related when the most supersensitive and the least supersensitive undercut cortices were compared.

(5) The decrease in the activity of $\mathrm{AChE}$ and the supersensitivity in undercut cortex are likely the consequences of the loss of cholinergic innervation and of synaptic disuse following denervation.

\section{ACKNOWLEDGEMENTS}

We wish to thank Miss Joyce Duncan and Mrs. Nell Beatty Cant for their valuable assistance with these experiments.

The work was supported by U.S. Public Health Grants NIH NDS 04119 (LTR) and NIH NDS 06294 (OZS).

\section{REFERENCES}

1 Bloom, F. E., AND BARRNeTt, R. J., The fine structural localization of cholinesterases in nervous tissue, Ann. N.Y. Acad. Sci., 144 (1967) 626-645.

2 Chu, N.-S., Rutledge, L. T., AND Sellinger, O. Z., Tubocurarine binding in undercut cerebral cortex and the effect of long-term electrical stimulation, Brain Research, 29 (1971) 331-337.

3 De Robertis, E., Alberici, M., Rodríguez de Lores Arnaiz, G., ANd Azcurra, J. M., Isolation of different types of synaptic membranes from the brain cortex, Life Sci., 5 (1966) 577-582.

4 Duncan, J. A., Rutledge, L. T., And Domino, E. F., Acetylcholinesterase activity in partially isolated cerebral cortex after prolonged intermittent stimulation, Exp. Neurol., 20 (1968) 268-274.

5 Echlin, F. A., AND BATTISTA, A., Decreased cholinesterase activity in epileptogenic chronically 'isolated' cerebral cortex, Trans. Amer. neurol. Ass., 87 (1962) 190-192.

6 EChlin, F. A., AND MCDonald, J., The supersensitivity of chronically isolated and partially isolated cerebral cortex as a mechanism in focal cortical epilepsy, Trans. Amer. neurol. Ass., 79 (1954) 75-79.

7 Ellman, G. L., Courtney, K. D., Andres, V., JR., and Featherstone, R. M., A new and rapid colorimetric determination of acetylcholinesterase activity, Biochem. Pharmacol, 7 (1961) 88-95.

8 Globus, A., ANd Scheibel, A. B., Synaptic loci on visual cortical neurons of the rabbit: The specific afferent radiations, Exp. Neurol., 18 (1967) 116-131. 
9 Grafstein, B., ANd Sastry, P. B., Some preliminary electrophysiological studies on chronic neuronally isolated cerebral cortex, Electroenceph. clin. Neurophysiol., 9 (1957) 723-725.

10 Green, J. R., Halpern, L. M., and Van Niel, S., Alterations in the activity of selected enzymes in the chronic isolated cerebral cortex of cat, Brain, 93 (1970) 57-64.

11 Hebs, C. O., KRnjević, K., AND Silver, A., Effect of undercutting on the acetylcholinesterase and choline acetyltransferase activity in the cat's cerebral cortex, Nature (Lond.), 198 (1963) 692.

12 KRnJević, K., AND Silver, A., A histochemical study of cholinergic fibers in the cerebral cortex, J. Anat. (Lond.), 99 (1965) 711-759.

13 Lewis, P. R., AND SHUTE, C. C. D., The distribution of cholinesterase in cholinergic neurons demonstrated with the electron microscope, J. Cell Sci., 1 (1966) 381-390.

14 Lowry, O. H., Rosebrough, N. J., Farr, A. L., And Randall, E. J., Protein measurement with the Folin phenol reagent, J. biol. Chem., 193 (1951) 265-275.

15 Navaratnam, V., and Lewis, P. R., Cholinesterase-containing neurones in the spinal cord of the rat, Brain Research, 18 (1970) 411-425.

16 Rosenberg, P., AND Echlin, F. A., Cholinesterase activity of chronic partially isolated cortex, Neurology (Minneap.), 15 (1965) 700-707.

17 Rosenberg, P., And Echlin, F. A., Time course of changes in cholinesterase activity of chronic partially isolated cortex, J. nerv. ment. Dis., 147 (1968) 56-63.

18 Rutledge, L. T., Effect of stimulation on isolated cortex. In H. H. JASPER, A. A. WARD, JR. AND A. Pope (Eds.), Basic Mechanisms of the Epilepsies, Little, Brown and Co., Boston, 1969, pp. 349-355.

19 Rutledge, L. T., Duncan, J. A., And Beatty, N., A study of pyramidal cell axon collaterals in intact and partially isolated adult cerebral cortex, Brain Research, 16 (1969) 15-22.

20 Rutledge, L. T., RaNCK, J. B., JR., AND DunCan, J. A., Prevention of supersensitivity in partially isolated cerebral cortex, Electroenceph. clin. Neurophysiol., 23 (1967) 256-262.

21 SEllinger, O. Z., AND BoRens, R. N., Zonal density gradient electrophoresis of intracellular membranes of brain cortex, Biochim. biophys. Acta (Amst.), 173 (1969) 176-184.

22 ShaRPLeSs, S. K., Reorganization of function in the nervous system. Use and disuse, Ann. Rev. Physiol., 26 (1964) 357-388.

23 Sharpless, S. K., and Halpern, L. M., The electrical excitability of chronically isolated cortex studied by means of permanently implanted electrodes, Electroenceph. clin. Neurophysiol., 14 (1962) 244-255.

24 VAlverde, F., Structural changes in the area striata of the mouse after enucleation, Exp. Brain Res., 5 (1968) 274-292. 